\title{
Meromelia in a Newborn- A Rare Congenital Anomaly
}

\author{
Deepak Chawla $\cdot$ Poonam Marwah
}

Received: 10 October 2013 / Accepted: 2 December 2013 /Published online: 21 January 2014

(C) Dr. K C Chaudhuri Foundation 2014

A term, $2.6 \mathrm{~kg}$, female child was born of a non consanguineous marriage to a primigravida via vaginal mode at the authors' institute. The child had major limb anomalies at birth. The right leg showed terminal transverse limb deficiency just below the knee joint while there was terminal transverse deficiency at distal third of left forearm (Fig. 1). Rest of the systemic examination was normal. Ultrasound head, abdomen and 2D echocardiography were normal. Family history and antenatal history (including drug intake, radiation exposure, febrile illness and rash) were negative. The antenatal ultrasound was done in first trimester only which was normal. The baby was asymptomatic and attached to pediatric orthopedic unit for rehabilitation and prosthesis at a later stage.

Limb defects are described as meromelia (partial absence) or amelia (complete absence) of one or more limbs. Phocomelia is a type of meromelia where rudimentary hands or feet are attached to trunk by small, irregularly shaped bones. The international society for prosthetics and orthotics (ISPO) classification describes limb deficiencies as either transverse (no distal skeletal remains- as index case) or longitudinal (has distal portions) [1]. Etiological factors include genetic, teratogens (infamous-thalidomide use), vascular disruptions and ischemia, chemicals and radiation exposure [2]. Children with limb anomalies have associated malformations like craniofacial, gastrointestinal, heart, kidney and nervous system. The present case was unique that child had only isolated limb meromelia with no other congenital anomalies.

Department of Pediatrics, Government Medical College

and Hospital, Sector-32, Chandigarh, India

P. Marwah $(\bowtie)$

House no 1457, Sector -9, HUDA, Ambala City,

Haryana 134003, India

e-mail: poonammehta73@gmail.com

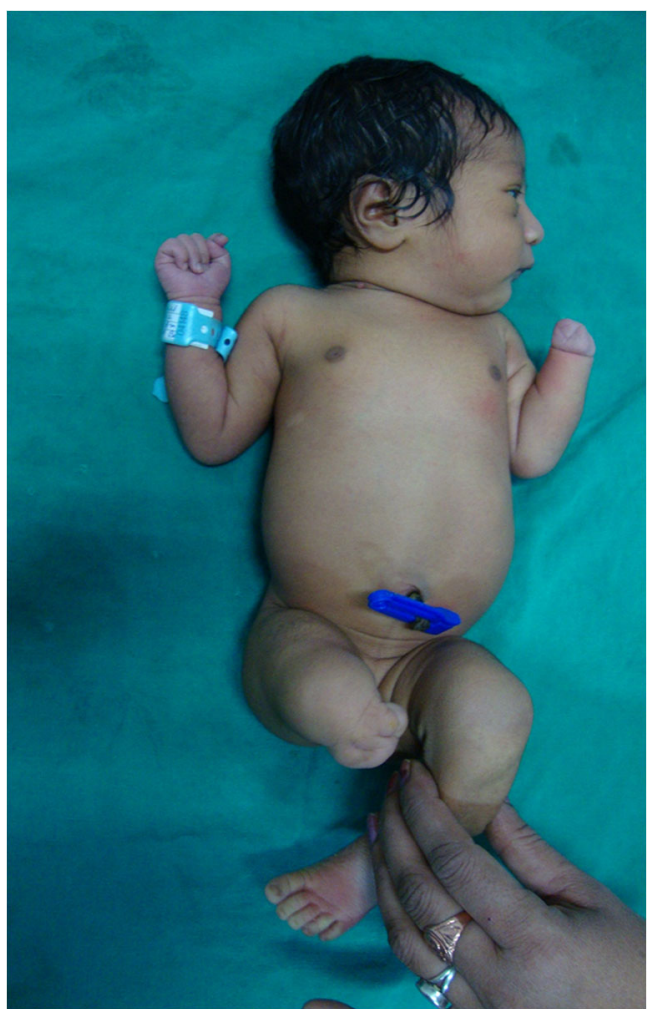

Fig. 1 Newborn with meromelic limb anomalies

Contributions PM: Drafted the manuscript and reviewed the literature; DC: Revised the manuscript and managed the case. He will act as guarantor for this paper.

Conflict of Interest None.

Role of Funding Source None.

\section{References}

1. Day HJ. The ISO/ISPO classification of congenital limb deficiency. Prosthet Orthot Int. 1991;15:67-9.

2. Moore KL, Persaud TVN, Torchia MG. Textbook of Essentials of Embryology and Birth Defects. The Musculoskeletal System. 7th ed. Philadelphia: John F. Kennedy; 2008. pp. 248. 